\title{
INGRESO PÚBLICO EN MÉXICO: UN ANÁLISIS ENTRE INGRESOS PETROLEROS Y CARGA FISCAL, 2006-2012
}

María Isabel García Morales*

(Recibido: mayo 2014/Aceptado: septiembre 2014)

\section{Resumen}

Este trabajo analiza la dependencia de los ingresos petroleros en el gobierno de Felipe Calderón Hinojosa (2006-2012), así como la composición de los rubros que integran los ingresos públicos federales, principalmente la relación entre los ingresos petroleros y los ingresos no petroleros. Se compara la carga fiscal de México con otros países latinoamericanos y la importancia que tienen los gobiernos estatales y municipales en la recaudación fiscal.

Palabras clave: carga fiscal, ingresos públicos, recaudación fiscal, ingresos petroleros, finanzas públicas.

Clasificación JEL: E62 H50 H61 H72 H77.

\section{Abstract}

This work analyzes the dependence of the oil revenues in the government of Felipe Calderon Hinojosa (2006-2012), and the composition of the items that integrate the federal government revenues, mainly the relationship

\footnotetext{
* Profesora-investigadora de la Sección de Estudios de Posgrado e Investigación, Escuela Superior de Economía del Instituto Politécnico Nacional. Correo: mgarciamor@ipn.mx.
} 
between the oil revenues and non-oil revenues. It compares the tax revenue of Mexico with some other Latin-American countries and the importance of state and local governments in tax collection.

Keywords: tax burden, public revenues, tax collection, oil revenues, public finance.

JEL classification: E62 H50 H61 H72 H77.

\section{Introducción}

Desde mediados de la década de los setenta, los ingresos provenientes de la exportación de petróleo crudo han representado un papel central en el financiamiento del Estado mexicano. Colmenares (1988) menciona que en los años anteriores al embargo petrolero de la OPEP (1969-1973) México era un importador neto de petróleo, un barril de petróleo tenía un precio inferior a dos dólares, mientras que su producción costaba más de cuatro dólares.

En 1974 al aumentar los precios del petróleo, México deja de importar e invierte en exploración y producción, se duplica la capacidad instalada entre los años 1974 a 1980 y se eleva el rango de papel estratégico de petróleos mexicanos (PEMEX) en el proceso de acumulación y de obtención de divisas para el desarrollo económico del país. Suárez (2001) concluye que durante el periodo 1974-1980 el consumo interno de petróleo se duplicó y PEMEX comenzó a ser el principal contribuyente de las finanzas públicas.

Según Ramírez (2013), en 1980, 1981 y 1982, los impuestos petroleros representaron respectivamente el 25\%, 26\% y 44\% de los ingresos ordinarios del Gobierno Federal. Mora (2009) señala que de 1997 a 2007 PEMEX transfirió al Gobierno Federal, alrededor de cuatro billones de pesos como pago de impuestos derechos y aprovechamientos, monto que equivalía al $60 \%$ de sus ventas totales a lo largo del periodo y al $38.6 \%$ del PIB para 2008.

Los ingresos provenientes de la extracción, procesamiento y venta de hidrocarburos han jugado un papel central en el financiamiento del Estado mexicano, actualmente representan una tercera parte de los ingresos de las finanzas públicas. La petrolización de las finanzas públicas se da como resultado de la fuerte contribución fiscal de PEMEX para financiar el gasto público federal. 
La hacienda pública mexicana se enfrenta a varios problemas, entre los más destacables está la insuficiencia de los recursos públicos para cubrir los requerimientos financieros del sector público, la baja carga fiscal y la fuerte dependencia financiera de los ingresos petroleros. En este trabajo se analizan estos dos últimos problemas en el sexenio de Felipe Calderón Hinojosa (2006-2012).

La hipótesis principal de este trabajo es que el aumento o disminución de la carga fiscal del gobierno federal en el último sexenio, dependió de las oscilaciones de los precios internacionales del petróleo.

Será importante en otros trabajos abordar qué sucederá con las "finanzas petrolizadas" ante las reformas energéticas y el nuevo régimen fiscal de PEMEX promovidas por el gobierno de Enrique Peña Nieto. Por ahora sólo nos enfocaremos a la importancia que tuvo el petróleo en el financiamiento de la hacienda pública federal en el gobierno de Felipe Calderón. En ocasiones, por considerarlo, importante se retoman datos desde 2001, porque comprende los gobiernos del Partido Acción Nacional (2000-2012).

En documento se divide en cuatro secciones. En la segunda sección, se analizan las finanzas públicas y su dependencia con el petróleo. La tercera sección, hace énfasis en la carga fiscal del Estado mexicano. En la cuarta sección, se analiza la presión fiscal que tienen los estados y municipios de México. Finalmente, se dan las conclusiones.

\section{Finanzas públicas petrolizadas}

La mayoría de los países clasifican sus ingresos públicos en tributarios y no tributarios, pero dado el gran peso que el petróleo tiene en las finanzas públicas mexicanas, los ingresos públicos federales se clasifican en ingresos petroleros e ingresos no petroleros.

\subsection{Ingresos petroleros e ingresos no petroleros}

Los ingresos tributarios son las percepciones que obtiene el gobierno federal por las imposiciones fiscales que en forma unilateral y obligatoria fija el Estado a personas físicas y morales, conforme a la ley para el financiamiento del gasto publico. Su carácter tributario atiende a la naturaleza unilateral y coercitiva de los impuestos, gravando diversas fuentes generadoras de 
ingresos; la compraventa, el consumo y las transferencias de tal forma que los ingresos tributarios son todos aquellos que provienen de impuestos, ya sean federales, estatales o municipales.

Los ingresos no tributarios son los ingresos que el gobierno federal obtiene como contraprestación a un servicio público (derechos) como el pago de uso de aprovechamiento o enajenación de bienes del dominio privado (productos), del pago de personas físicas y morales que se benefician de manera directa de obras públicas (contribución de mejoras) y por los ingresos ordinarios provenientes por funciones de derecho público, distinto de impuestos, es decir, son todos los ingresos que no provienen de impuestos, queda excluido el financiamiento (deuda pública) o donaciones.

Como se puede apreciar en el cuadro 1, el Estado mexicano enfrenta gran dependencia de los ingresos petroleros, en promedio del 2001 al 2012 el 31.5\% de los ingresos del gobierno provinieron del petróleo, es decir, que casi una tercera parte de sus ingresos se derivaron de los ingresos petroleros.

De tal forma que el financiamiento del gasto público se basa en un porcentaje muy considerable de recursos que provienen del petróleo, lo que hace vulnerable el financiamiento del Estado debido a las oscilaciones de los precios internacionales del mismo. Si el precio internacional del barril aumenta, el país se beneficia, pero si el precio cae, está latente un recorte o ajuste del gasto público, con todas las consecuencias económicas, sociales y políticas que esto implica.

También se puede observar que de 2002 a 2012, casi en todos los años, al caer los precios del petróleo cae el porcentaje de los ingresos petroleros, pero también se resalta un aspecto importante, hay una tendencia a la baja de la producción de petróleo, lo cual también afecta a las finanzas públicas. Es importante mencionar que aunque PEMEX también produce gas, petrolíferos y petroquímicos, el petróleo es el principal producto de exportación, representa cerca del $70 \%$ de las ventas al exterior. 


\section{Cuadro 1}

Ingresos públicos del gobierno federal, producción

y precios del petróleo, 2002-2012

\begin{tabular}{|l|c|c|c|c|c||}
\hline \multirow{2}{*}{ Año } & \multicolumn{3}{|c|}{ Ingresos público } & \multirow{2}{*}{$\begin{array}{c}\text { Precios por barril } \\
\text { en dólares }\end{array}$} & $\begin{array}{c}\text { Producción } \\
\text { de crudo } \\
\text { (millones de } \\
\text { barriles/día) }\end{array}$ \\
\cline { 2 - 6 } & $\begin{array}{c}\text { Petroleros } \\
\text { (porcentajes) }\end{array}$ & $\begin{array}{c}\text { No petroleros } \\
\text { (porcentajes) }\end{array}$ & Total & 21.5 & 3.177 \\
\hline 2002 & 26.3 & 73.7 & 100 & 24.7 & 3.371 \\
\hline 2003 & 31.6 & 68.4 & 100 & 31.0 & 3.383 \\
\hline 2004 & 35.2 & 64.8 & 100 & 42.7 & 3.333 \\
\hline 2005 & 38.3 & 61.7 & 100 & 53.0 & 3.256 \\
\hline 2006 & 34.9 & 65.1 & 100 & 61.4 & 3.076 \\
\hline 2007 & 29.6 & 70.4 & 100 & 84.3 & 2.792 \\
\hline 2008 & 33.8 & 66.2 & 100 & 57.4 & 2.601 \\
\hline 2009 & 25.1 & 74.9 & 100 & 72.4 & 2.576 \\
\hline 2010 & 28.8 & 71.2 & 100 & 101 & 2.550 \\
\hline 2011 & 31.0 & 69.0 & 100 & - & - \\
\hline 2012 & 29.9 & 70.1 & 100 & & \\
\hline
\end{tabular}

a) Incluye ingresos tributarios (vía impuestos) e ingresos no tributarios (derechos, productos, aprovechamientos y contribución de mejoras).

Fuente: elaboración propia con base en datos de INEGI y PEMEX.

Se observa que de 2005 a 2010 los ingresos petroleros tuvieron una caída como fuente de financiamiento del gobierno federal de 10 puntos porcentuales, pasó de $38.3 \%$ a $28.8 \%$, se aprecia que aunque los precios del petróleo en general subieron también cayó la producción del petróleo. Si comparamos 2005 con 2009, este último año de crisis económica, la disminución fue aún mayor, 13.2 puntos porcentuales.

En la gráfica 1 se visualiza la importancia de los ingresos petroleros y no petroleros del 2002 al 2012 en la composición de los ingresos públicos del gobierno federal. En 2006 los ingresos petroleros del gobierno federal fueron equivalentes al $34.9 \%$ de los ingresos totales, se observa una disminución considerable, en 2010 representaron el 28.8\%. En 2009, ante la crisis mundial, cayeron a 25.1\%. Para el 2011 los ingresos petroleros tuvieron un repunte, para representar el 31\% de los ingresos gubernamentales. 


\section{Gráfica 1}

Ingresos petroleros e ingresos no petroleros, 2002-2012

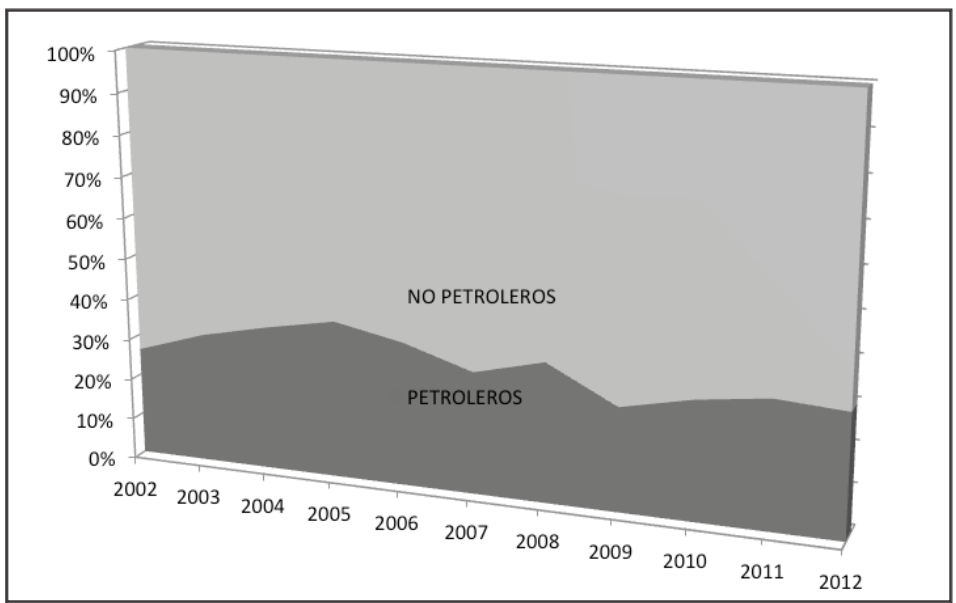

Fuente: elaboración propia con base en datos de INEGI y PEMEX.

\subsection{Ingresos públicos en el gobierno de Felipe Calderón, 2006-2012}

En 2009, el gobierno panista ${ }^{1}$ de Felipe Calderón Hinojosa, en un contexto de crisis económica mundial, se enfrenta a una caída de los precios del petróleo, disminución de la producción petrolera, contracción de la actividad económica con su respectiva disminución de la recaudación fiscal. Ante esta situación él propone una reforma fiscal.

Los principales argumentos del gobierno federal en la reforma fiscal de 2009 (vigente hasta diciembre de 2013) fueron disminuir la dependencia de los ingresos petroleros y cubrir el boquete fiscal que había generado la caída del crecimiento económico. Sin embargo, al final del sexenio de Felipe Calderón la dependencia de los ingresos petroleros no disminuyó sino aumentó.

Es necesario aclarar que el aumento de los ingresos no petroleros que se observa en el cuadro 1 no significó un aumento monetario de éstos sino que, simplemente, al disminuir los ingresos petroleros, en términos porcentuales aumentaron los no petroleros. En general la recaudación del gobierno federal

\footnotetext{
${ }^{1}$ Partido de Acción Nacional (PAN), gobernó a nivel federal 2000-2012. Vicente Fox Quezada de 20002006 y Felipe Calderón Hinojosa de 2006-2012.
} 
disminuyó y con ello, los ingresos del gobierno mexicano se vieron seriamente mermados.

En 2009, con la disminución de los ingresos petroleros y la contracción de la actividad económica, se calculó para el ejercicio fiscal de 2010 un boquete fiscal de 300 mil millones de pesos (25000 millones de dólares). ${ }^{2}$ Para cubrir sus gastos el gobierno mexicano incrementó casi todos los impuestos. ${ }^{3}$ Esta acción fue muy criticada por los partidos de oposición, ya que en plena contracción económica, se aplicó una política fiscal restrictiva, disminuyendo con ello todavía más la demanda agregada.

En esta reforma fiscal -como ya se dijo-, vigente hasta diciembre de 2013, el impuesto al valor agregado (IVA) pasó del 15 al 16\% (10 al 11\% en la zona fronteriza). El impuesto sobre la renta (ISR) se incrementó del 28 al 30\%. El impuesto a depósitos en efectivo (IDE) pasó del 2\% a depósitos en efectivo mayores de 25000 pesos a 3\% a depósitos en efectivo mayores de 15,000 pesos. El impuesto especial sobre productos y servicios (IEPS) también aumentó, por ejemplo; la cerveza de $25 \%$ a $26.5 \%$, cigarros a una tasa de $160 \%$ más $\$ 0.04$ por cigarro en 2010, \$0.06 -2011, \$0.08 -2012, \$0.10 -2013, juegos y sorteos pasó de 20 al 30\%, bebidas alcohólicas más de $20^{\circ} \mathrm{GL}$, de $50 \%$ a 53\%, gasolina, magna 36 centavos por litro, premium 43.92 centavos por litro, diesel 29.88 centavos por litro, telecomunicaciones $3 \%{ }^{4}$

¿Qué medidas tomó el gobierno federal ante una disminución del ingreso público y una tendencia de aumento del gasto público? Como ya se explicó una medida fue el incremento de casi todos los impuestos y la otra, la contratación de deuda pública. La deuda pública interna en el gobierno de Vicente Fox, 2000-2006, fue de un billón 500 millones de pesos (83 375 millones de dólares), pero para el gobierno de Felipe Calderón en 2008 alcanzaba los dos billones 332 mil millones de pesos (94,333 millones de dólares) en dos años (de 2006 a 2008) aumento el 55.5\%.

La deuda pública interna contratada en 2011 por el sector público en el mercado financiero rebasó los cuatro billones de pesos (cuatro billones 24 mil 72.9 millones de pesos), es decir, 335 mil millones de dólares, es el principal pasivo que enfrenta el gobierno federal y las entidades federativas. Esta cantidad equivalía en 2010 al 27\% del PIB.

\footnotetext{
2 Tipo de cambio de 12 pesos por dólar.

${ }^{3}$ El gobierno de Peña Nieto (2012-2018) para su primera ley de ingresos implementó otra reforma fiscal.

${ }^{4}$ Ley de Ingresos de la Federación para el ejercicio fiscal 2010.
} 
El gobierno federal (2006-2012) recurrió a la emisión de valores de deuda pública a través de certificados de la tesorería (CETES) ${ }_{1}^{5}$ bonos de desarrollo del gobierno federal, bonos de desarrollo del gobierno federal denominados en unidades de inversión (UDIBONOS). Además de los cuatro billones 24 mil 72.9 millones de pesos de deuda pública interna al cierre del 2011, se debe sumar el saldo de la deuda pública externa que al cierre de enero del 2012 llegó a 115 mil 781 millones de dólares.

El principal argumento del gobierno federal, en 2009, para incrementar los impuestos, fue disminuir la dependencia de los recursos petroleros. La reforma fiscal de 2009, que se aplicó a partir del 1 enero de 2010 y se mantuvo vigente hasta el 31 de diciembre del 2013, poco sirvió para reducir dicha dependencia, al cierre del sexenio de Felipe Calderón las finanzas públicas terminaron tan petrolizadas como al inicio del mismo.

La dependencia de los ingresos petroleros por parte del Estado mexicano ha generado un sistema de recaudación tributaria sumamente ineficiente, que se refleja en una baja presión fiscal si se compara con los países latinoamericanos de desarrollo similar como son Brasil y Argentina.

\section{Presión y carga fiscal del Estado mexicano}

Es importante hacer una diferenciación para efectos de este trabajo entre carga fiscal y presión fiscal. La carga fiscal es la parte del producto social generado que toma el Estado, mediante los impuestos federales, estatales y municipales, así como los derechos, productos y aprovechamientos para cumplir con sus funciones. Entonces, entendemos para este trabajo por carga fiscal, aquella parte de la riqueza que el Estado obtiene de la sociedad para hacer frente a sus responsabilidades de diversa índole, además de los impuestos, puede incluir otra fuente de ingresos, excepto contratación de deuda. Para el caso de México, INEGI incluye los ingresos petroleros.

Y por presión fiscal, se entiende la relación por cociente entre los ingresos coactivos (detracción impositiva) del sector público y la renta nacional o

\footnotetext{
${ }^{5}$ Los CETES (Certificados de la Tesorería) son títulos de crédito al portador emitidos por el Gobierno Federal desde 1978, en los cuales se consigna la obligación de éste a pagar su valor nominal al vencimiento. Dicho instrumento se emitió con el fin de influir en la regulación de la masa monetaria, financiar la inversión productiva y propiciar un sano desarrollo del mercado de valores. A través de este mecanismo se captan recursos de personas físicas y morales a quienes se les garantiza una renta fija. El rendimiento que recibe el inversionista consiste en la diferencia entre el precio de compra y venta (Banco de México, 2013).
} 
producto interno bruto es decir, parte de la riqueza de la sociedad que el estado obtiene vía tributación, también incluye, productos, derechos y aprovechamientos. Este indicador mide el grado de esfuerzo fiscal de un país (la presión fiscal no contempla ingresos petroleros).

En el cuadro 2 podemos apreciar tanto la carga fiscal como la presión fiscal del gobierno federal, gobiernos estatales y municipales.

Cuadro 2

Capacidad financiera del estado mexicano

\begin{tabular}{|l|c|c|c|c|c|c|c|}
\hline \multicolumn{1}{|c|}{ Rubro/año } & 2007 & 2008 & 2009 & 2010 & 2011 & 2012 \\
\hline \multicolumn{1}{|c|}{ PIB } & 100 & 100 & 100 & 100 & 100 & \\
\hline $\begin{array}{l}\text { Ingresos del gobierno federal. Incluye } \\
\text { ingresos petroleros (carga fiscal) }\end{array}$ & 16.2 & 19.1 & 17.6 & 17.0 & 16.4 & 16.4 \\
\hline $\begin{array}{l}\text { Ingresos sólo por impuestos (presión } \\
\text { fiscal) }\end{array}$ & $(9.6)$ & $(10.2)$ & $(9.9)$ & $(10.5)$ & $(9.6)$ & $(9.6)$ \\
\hline $\begin{array}{l}\text { Ingresos de gobiernos estatales (carga } \\
\text { fiscal) }\end{array}$ & 0.6 & 0.9 & 0.7 & 0.6 & 0.7 & 0.7 \\
\hline $\begin{array}{l}\text { Ingresos sólo por impuestos de go- } \\
\text { biernos estatales (presión fiscal) }\end{array}$ & $(0.2)$ & $(0.3)$ & $(0.3)$ & $(0.3)$ & $(0.3)$ & $(0.3)$ \\
\hline $\begin{array}{l}\text { Ingresos de gobiernos municipales } \\
\text { (carga fiscal) }\end{array}$ & 0.4 & 0.5 & 0.4 & 0.4 & 0.4 & 0.4 \\
\hline $\begin{array}{l}\text { Ingresos sólo por impuestos munici- } \\
\text { pales (presión fiscal) }\end{array}$ & $(0.2)$ & $(0.3)$ & $(0.2)$ & $(0.2)$ & $(0.2)$ & $(0.2)$ \\
\hline
\end{tabular}

Fuente: elaboración propia con base en datos de INEGI.

La presión fiscal del gobierno federal de 2008 a 2011 fue en promedio del $10.5 \%$ del PIB, los ingresos petroleros en este periodo representaron el $7.8 \%$ del PIB, la carga fiscal (incluye ingresos petroleros) en los mismo años fue de $18.3 \%$, mientras que los requerimientos financieros del sector publico ${ }^{6}$ rondaron en torno al 34\% del PIB (SHyCP, 2011 Balance Fiscal: 19). El gobierno federal no recauda los ingresos necesarios para hacer frente a todos sus requerimientos financieros, aun echando mano de los ingresos petroleros.

\footnotetext{
${ }^{6}$ Los requerimientos financieros del sector publico, son las necesidades de financiamiento para alcanzar los objetivos de las políticas públicas del gobierno federal. Éste es un indicador más amplio para evaluar el cambio en las obligaciones financieras del sector público derivado de las transacciones que realiza. (SHyCP, 2011 Balance Fiscal: 19).
} 


\subsection{Carga fiscal y precios del petróleo}

El cuadro 3 nos demuestra como la carga fiscal aumenta o disminuye, casi siempre, en relación directa a los precios internacionales del petróleo o al volumen de la producción de petróleo.

\section{Cuadro 3}

Carga fiscal por nivel de gobierno del Estado mexicano (Porcentaje con respecto al producto interno bruto)

\begin{tabular}{|l|r|r|r|r|r|r|r|r|}
\hline \multicolumn{1}{|c|}{ Orden de gobierno } & $\mathbf{2 0 0 5}$ & $\mathbf{2 0 0 6}$ & $\mathbf{2 0 0 7}$ & $\mathbf{2 0 0 8}$ & $\mathbf{2 0 0 9}$ & $\mathbf{2 0 1 0}$ & $\mathbf{2 0 1 1}$ & $\mathbf{2 0 1 2}$ \\
\hline Ingresos del gobierno federal & 15.8 & 16.1 & 16.2 & 19.1 & 17.6 & 17.0 & 16.4 & 16.4 \\
\hline Ingresos del gobierno estatal & 0.5 & 0.6 & 0.6 & 0.9 & 0.7 & 0.6 & 0.7 & 0.7 \\
\hline Ingresos del gobierno municipal & 0.4 & 0.4 & 0.4 & 0.5 & 0.4 & 0.4 & 0.4 & 0.4 \\
\hline Producto interno bruto & 100 & 100 & 100 & 100 & 100 & 100 & 100 & 100 \\
\hline
\end{tabular}

Fuente: elaboración propia con base en datos de INEGI.

Los precios internacionales del petróleo en 2007 eran de 61.4 dólares por barril y en 2008 de 84.3 dólares y aunque la producción de un año a otro bajo de 3076 millones de barriles por día (mbd) a $2792 \mathrm{mbd}$, el aumento de los precios del petróleo, hicieron incrementar los ingresos petroleros del país, con ello observamos en el cuadro 3 un aumento de la carga fiscal, de un año para otro se observa que la carga fiscal pasó de 2007 a 2008 de 16.2\% a $19.1 \%$, es decir, aumentó en un solo año $2.9 \%$, casi tres puntos porcentuales del PIB, sólo por efecto de los precios del petróleo sin que ello haya implicado un aumento en los esfuerzos de recaudación fiscal.

Pero también se observa el efecto contrario, la caída de los precios del petróleo, de 2008 a 2009, implicó un caída de la carga fiscal de 1.5 puntos porcentuales con respecto del PIB, pasó de $19.1 \%$ al $17.6 \%$, aquí se conjugaron los dos elementos la caída del precio del barril de 84.3 a 57.4 dólares por barril y una caída de la producción de 2601 a 2576 millones de barriles por día.

El aumento o disminución de la carga fiscal del gobierno mexicano está determinada en gran medida por los precios internacionales del petróleo, los datos de los cuadros 1 y 3 demuestran la gran vulnerabilidad que tienen 
las finanzas públicas mexicanas de los precios internacionales del petróleo y de su producción.

\subsection{Presión fiscal del gobierno federal}

Oates (1977) menciona que el principal mecanismo de financiamiento para la mayoría de los gobiernos, deberían ser los ingresos tributarios (impuestos) y los no tributarios (cobro de derechos, aprovechamientos, productos), cuando éstos son predominantes en las finanzas del Estado, podemos presuponer una hacienda pública fuerte y eficiente, y de alguna manera la existencia de grandes esfuerzos recaudatorios de las instituciones hacendarias. En el caso de México, las cosas no suceden de este modo.

Díaz (2012), en una evaluación que realiza sobre la política tributaria del gobierno de Felipe Calderón, señala que de 2007 a 2012 el aumento de la recaudación fue tan sólo del $0.3 \%$ de variación real, muy por debajo de la inflación real promedio del $4.56 \%$, no hubo aumentos considerables en términos del PIB, los ingresos tributarios sólo se incrementaron $0.4 \%$.

En su trabajo sobre opacidad y transparencia en México Acosta (2013) señala que México tiene serios problemas de administración tributaria, puntualiza que hace una década por cada dos pesos que hubieran debido ingresar a las arcas públicas, el Servicio de Administración Tributaria (SAT), entidad encargada de recaudar los impuestos en México, sólo cobraba poco más de un peso. Lo que significaba que casi el 50\% del potencial recaudatorio en México se perdía en evasión, elusión, fraudes, y otras irregularidades de carácter tributario.

Y además refiere: "La práctica nos ha enseñado que cuando se suben las tasas, cuando se amplían las bases de tributación o cuando se crean nuevos impuestos, rara vez se logran los resultados esperados, quienes antes de una reforma evadían lo seguirán haciendo si no perciben que es más peligroso" (Acosta, 2013).

Acosta también señala que la entidad fiscalizadora de la federación, la Auditoría Superior de la Federación (ASF), al practicar auditorias financieras y analizar el desempeño de las autoridades hacendarias, ha determinado que los ingresos tributarios muestran una tasa media anual de crecimiento del 5.4\% a valores nominales en el periodo 2001-2007; sin embargo, su participación respecto del total de los ingresos fiscales del gobierno federal refleja una disminución del 12\%, al pasar del 70\% en 2001 al $58 \%$ en 2007. 


\title{
3.3. Carga fiscal de México y países de América Latina
}

En el cuadro 4, con datos de la Comisión Económica para América Latina (CEPAL), se puede apreciar la carga fiscal de 2000 a 2011 de varios países latinoamericanos.

\author{
Cuadro 4 \\ América Latina, carga fiscal, 2000-2011 \\ (en porcentaje del PIB)
}

\begin{tabular}{|c|c|c|c|c|c|}
\hline \multirow{2}{*}{ País } & \multicolumn{2}{|c|}{ Ingresos totales } & \multirow{2}{*}{ País } & \multicolumn{2}{|c|}{ Ingresos totales } \\
\hline & 2000 & 2011 & & 2000 & 2011 \\
\hline \multicolumn{3}{|c|}{ Grupo 1} & \multicolumn{3}{|c|}{ Grupo 2} \\
\hline Argentina & 25 & 38 & Paraguay & 18.1 & 21.7 \\
\hline Brasil & 32.5 & 38.3 & Honduras & 16.2 & 18.3 \\
\hline Uruguay & 27.4 & 29 & El Salvador & 14.2 & 17.1 \\
\hline \multicolumn{3}{|c|}{ Grupo 2} & \multicolumn{3}{|c|}{ Grupo 3} \\
\hline Bolivia & 26.7 & 34.5 & Haití & 8.2 & 14.3 \\
\hline Costa Rica & 21.3 & 24.1 & Guatemala & 14.1 & 13.6 \\
\hline Chile & 21.9 & 24.6 & República & 13.3 & 13.5 \\
\hline Ecuador & 19 & 31.2 & \multirow{3}{*}{\begin{tabular}{|l|} 
Venezuela \\
México \\
\end{tabular}} & \multirow{2}{*}{20.9} & \multirow{2}{*}{23} \\
\hline Nicaragua & 16.8 & 21.8 & & & \\
\hline Colombia & 17.7 & 22.4 & & $1 / .4$ & 19.5 \\
\hline Panamá & 24.6 & 243 & \multicolumn{3}{|c|}{ Grupo 4} \\
\hline Perú & 17 & 19.4 & $\begin{array}{l}\text { El Caribe } \\
(13 \text { países })^{*}\end{array}$ & 24.5 & 28.3 \\
\hline
\end{tabular}

*Excepto Cuba, en el 2000 tuvo ingresos del 48.8 \%con respecto del PIB y en 2011 del 65.7\%. Fuente: elaboración propia con base en datos de CEPAL.

La mayoría de los países de América Latina tuvieron de 2000 a 2011 un marcado crecimiento de su carga fiscal, la CEPAL atribuye este crecimiento a varios factores entre ellos el incremento de sostenido del precio internacional de productos básicos y minerales y a los esfuerzos recaudatorios de varios países.

La CEPAL clasifica a los países en grupos de acuerdo con el nivel de carga tributaria media. En el grupo 1 se ubican los países en más de un $20 \%$ por encima del promedio regional, el grupo 2 los que se encuentran en torno al 20\% 
respecto a ese valor y grupo 3 aquellos cuya carga tributaria es al menos un $20 \%$ inferior a ese nivel.

El crecimiento de la carga tributaria ha sido muy heterogéneo, debido a la implementación de distintas políticas tributarias (CEPAL, 2013: 11). Brasil y Argentina son los que más carga tributaria tuvieron, mientras México se encuentra entre los más bajos al igual que Venezuela, a pesar de que ambos países cuentan con ingresos petroleros.

De 2000 a 2011, México pasó de $17.4 \%$ a 19.5\%, sólo incrementó 2.1 puntos porcentuales su carga fiscal, aunque ya lo hemos comentado anteriormente, ésta aumentó o disminuyó en función de los precios internacionales del petróleo más que de esfuerzos recaudatorios. Argentina fue el país que más incrementó su carga fiscal, pasó en el mismo periodo de 25 a 38\%, tuvo un incremento de 13 puntos porcentuales, ello se debió a la instauración de derechos a la exportación a partir del 2002 y al incremento de la recaudación por contribución a la seguridad social como resultado de la nacionalización del sistema en 2008.

Se observa que Argentina y Brasil tuvieron una carga fiscal por encima del promedio de los países latinoamericanos, ambos gobiernos financian la mayor parte de sus actividades con ingresos tributarios, lo cual refleja un sistema fiscal más eficiente, en comparación con México y Venezuela

\section{Presión fiscal de los estados y municipios en México}

En México también el nivel de recaudación fiscal de los estados y municipios es muy baja (cuadro 2), en 2009 la presión fiscal de los estados representó el $0.3 \%$ con respecto del PIB y los municipios el $0.2 \%$. La gran dependencia de las transferencias financieras del gobierno federal han desincentivado la recaudación fiscal en sus jurisdicciones.

Según Oates (1977) cada nivel de gobierno debe obtener los recursos, vía impuestos, para brindar los servicios y cumplir las funciones que en ese nivel le corresponden, ello implica que cada individuo debe soportar el gasto público y deuda de su comunidad, vía impuestos. Los datos del cuadro 2 revelan que las entidades federativas no recaudan los ingresos que ese nivel de gobierno requiere.

En la literatura fiscal existen varios sistemas de coordinación fiscal y en la práctica predominan el sistema de separación de impuestos y el sistema concurrente. En México con la Ley de Coordinación Fiscal de 1980 se crea 
el Sistema Nacional de Coordinación Fiscal, a partir de éste se establece un sistema global de participaciones calculado sobre el total de los ingresos de la Federación por concepto de impuestos. La adhesión de las entidades federativas al Sistema Nacional de Coordinación Fiscal (SNCF) implicó que los estados renunciaran a su soberanía tributaria, es decir, cedieran sus potestades tributarias al gobierno federal. Esto explica, en parte, su baja presión fiscal.

En términos fiscales se eliminó la concurrencia impositiva y la doble tributación, pero en términos institucionales significó un atraso, porque se incrementó la dependencia financiera de los estados con respecto de las transferencias del gobierno federal. Actualmente el SNCF, subordina financieramente a los estados y municipios, ellos dependen, en promedio, de un $90 \%$ de las transferencias financieras federales.

El hecho de que en México los gobiernos estatales y municipales tengan pocas potestades tributarias que además son reducidamente significativas en términos de su aportación monetaria en comparación con las del gobierno federal, repercuten en la baja carga fiscal del Estado mexicano.

\subsection{Ingresos tributarios de gobiernos subnacionales en México, Brasil y Ar- gentina}

Se puede apreciar en el siguiente cuadro que en Argentina y Brasil, países con desarrollo económico similar al de México, los gobiernos estatales y municipales tienen una importancia mucho mayor en la recaudación fiscal que en México.

\section{Cuadro 5}

Ingresos tributarios en los subsectores del gobierno federal como porcentaje del ingreso tributario total en 2010

\begin{tabular}{|l|c|c|c|c|c|}
\hline \multicolumn{1}{|c|}{ Países } & $\begin{array}{c}\text { Gobierno } \\
\text { central }\end{array}$ & $\begin{array}{c}\text { Gobierno } \\
\text { estatal o } \\
\text { regional }\end{array}$ & $\begin{array}{c}\text { Gobierno } \\
\text { municipal }\end{array}$ & $\begin{array}{c}\text { Fondo de } \\
\text { seguridad } \\
\text { social }\end{array}$ & $\begin{array}{c}\text { Ingresos } \\
\text { tributarios } \\
\text { totales }\end{array}$ \\
\hline Argentina & 64.6 & 14.2 & & 21.2 & 100 \\
\hline Brasil & 45.9 & 23.9 & 4.1 & 26.0 & 100 \\
\hline México & 81.1 & 2.4 & 1.2 & 15.4 & 100 \\
\hline
\end{tabular}

Fuente: elaboración propia con base en datos de OECD y ECLAC. 
Según García (2011), en Brasil, los gobiernos estatales y municipales recaudan casi el 30\% de los ingresos tributarios, lo que sin duda les da una mayor autonomía financiera que los gobiernos subnacionales en México. En Argentina los estados recaudan el 15\% de los ingresos tributarios, los municipios, a pesar de ser un gobierno federalista, no tienen potestades tributarias, es decir, no cobran impuestos aunque sí servicios públicos, como el de alumbrado, barrido y limpieza.

\section{Conclusiones}

El objetivo de este trabajo es analizar la dependencia de los ingresos petroleros en el gobierno de Felipe Calderón Hinojosa, así como la composición de los rubros que integran los ingresos públicos federales. La hipótesis principal de este trabajo se comprueba; el aumento o disminución de la carga fiscal del Estado mexicano, en el último sexenio, dependió en gran medida de los precios internacionales del petróleo, de manera que los recursos financieros del gobierno federal, están sumamente relacionados con los precios internacionales del petróleo, si éstos aumentan la hacienda pública se ve beneficiada, pero si éstos bajan sucede lo contrario, y los ajustes al gasto público son inminentes, esta situación conlleva a una gran vulnerabilidad de las finanzas públicas.

A partir de 2006, México muestra una tendencia a la caída en la producción petrolera, lo que sin duda también tiene sus repercusiones sobre los ingresos del gobierno federal. Se observa que en el sexenio de Felipe Calderón, en algunos años, los ingresos petroleros disminuyeron como proporción de los ingresos del gobierno federal, pero ello no se tradujo en una reducción de la dependencia de los ingresos petroleros o en un aumento de la recaudación tributaria, simplemente implicó una reducción de los ingresos, los cuales fueron resarcidos con deuda pública.

En 2009, con la disminución de los ingresos petroleros, el gobierno mexicano incrementó los impuestos. De manera que la política fiscal aplicada no ayudó a la recuperación de la actividad económica. La dependencia de los ingresos petroleros por parte del Estado mexicano ha generado un sistema de recaudación tributaria sumamente ineficiente, que se refleja en una baja presión fiscal si se compara con los países latinoamericanos de desarrollo similar como son Brasil y Argentina.

Los estados y municipios tienen también una baja carga fiscal, en parte, por la forma como funciona el sistema nacional de coordinación fiscal, en la 
que los estados cedieron sus potestades tributarias a la federación a cambio de recibir recursos coparticipados de los impuestos, esta situación ha hecho a los estados sumamente dependientes de las transferencias federales.

El hecho de que en México los gobiernos estatales y municipales tengan pocas potestades tributarias, repercute en la baja carga fiscal del Estado mexicano. En México, las entidades federativas y los municipios tienen una baja participación en la recaudación de los ingresos fiscales, es fundamental revisar el Sistema Nacional de Coordinación Fiscal para que estos gobiernos subnacionales tengan mayores recursos propios y contribuyan con una mayor carga fiscal, como sucede en Brasil y Argentina. Los recursos públicos del gobierno federal, aun tomando en cuenta los ingresos tributarios, son insuficientes para cubrir los Requerimientos Financieros del Sector Público mexicano.

\section{Referencias}

Acosta Villada, Aurelio (2012). "Opacidad de las finanzas públicas en México", Calderón José María, coord. Hacienda Pública, Política Fiscal y los límites de la Democracia, Ed. UNAM, México, pp. 180-210.

Astudillo Moya, Marcela (1999). El federalismo y la coordinación impositiva en México. Instituto de Investigaciones Económicas UNAM- Porrúa, México.

Astudillo Moya, Marcela (2001). "Finanzas locales", Arriaga Conchas Enrique, coord. Finanzas públicas de México, 2ª ed., IPN, México, pp. 295-337.

Ayala Espino, José (2005). Economía del sector público mexicano. Editorial Esfinge, México, pp. 23-25.

Barbosa Cano, Fabio (1994). Recursos petroleros de México, 1974-1994. Estudios e informes de México y Estados Unidos. Ed. IIEc-UNAM, México. 
Calderón Rodríguez, José María (1998). El federalismo fiscal y las relaciones intergubernamentales en México, economía y política. Facultad de Economía-UNAM, tesis de doctorado, México, DF., pp. 303-320

CEPAL (2013), Panorama fiscal de América Latina y el Caribe. Reformas tributarias y renovación del pacto fiscal. División de Desarrollo Económico. www.cepal.org/ ofilac/noticias/paginas/3/43813/2013-105-Panorama_Fiscal-WEB.pdf consultada 1 de septiembre de 2013.

Colmenares, Francisco (1988). "Problemas de rentabilidad y productividad de la industria petrolera mexicana, 1970-1984", UNAM. Tesis de maestría. México, DF., pp. 42-50.

Díaz Pérez, Miguel Ángel (2012). “Evaluación de la política tributaria en México, 2007-2012", Revista Finanzas Públicas, vol. 4, núm. 7, pp. 8-44, México.

García Morales, María Isabel (2011). “Federalismo y descentralización. El caso de la Provincia de Buenos Aires y La Matanza, Argentina". UNAM Tesis de doctorado. México, D.F.

INEGI (2011, 2012, 2013). El ingreso y el gasto público en México. Series de estadísticas sectoriales, México.

Mora, Francisco (2009). "Inversión y renta petrolera en el financiamiento del déficit fiscal el modelo PIDIREGAS 1997-2008”, México, disponible en: www.diputados.gob.mx/UEC, pp. 146.

Oates, Wallace E. (1977). Federalismo Fiscal Nuevo Urbanismo, 1ª ed., Instituto de Estudios de Administración Local, España., pp. 174-178

OECD-ECLAC (2012). "Revenue statistics in Latin America, tax revenue trends 1990-2010. PEMEX (2012)", Anuario Estadístico. Apartado 1.2 Principales estadísticas opertivas consolidadas, consultado 13 septiembre del 2012, en http://www. ri.pemex.com/files/content/Anuario\%20Estadistico\%202012.pdf.

Pérez Torres, Javier y Ignacio González Hernández (1997). “La descentralización fiscal en México". Serie Política Fiscal No. 106, Proyecto Regional de Descentralización Fiscal, CEPAL/GTZ, pp. 42.

Ramírez Murillo, Karla (2013). Ingresos presupuestarios petrolizados, Ed. UNAM, México, pp. 4-8.

Retchkiman, Benjamín (1975). "Aspectos estructurales de la economía pública", Textos Universitarios. UNAM. México, pp. 19-20.

SHyCP (2011), "Balance Fiscal en México. Definición y metodología".

Suárez, Sergio y Isaac Palacios (2001). Pemex y el desarrollo económico mexicano: aspectos básicos. Ed. Textos breves economía, UNAM, México, p. 39. 